\title{
Breast Cancer pN3 TNM Finding v7
}

National Cancer Institute

\section{Source}

National Cancer Institute. Breast Cancer pN3 TNM Finding v7. NCI Thesaurus. Code C88361.

Breast cancer with metastases in 10 or more axillary lymph nodes; or in infraclavicular (level III axillary) lymph nodes; or in clinically detected ipsilateral internal mammary lymph nodes in the presence of 1 or more positive level I, II axillary lymph nodes; or in more than 3 axillary lymph nodes and in internal mammary lymph nodes with micrometastases or macrometastases detected by sentinel lymph node biopsy but not clinically detected; or in ipsilateral supraclavicular lymph nodes. (from AJCC 7th Ed.) 